\title{
The Realistic Dilemma of Mutual Aid for the Aged in Rural Areas and Solutions
}

\author{
Kang Jianying ${ }^{1, *}$, Wang Jiale ${ }^{2}$ \\ ${ }^{1}$ School of Public Administration, Hebei University of Economics and Business \\ ${ }^{2}$ School of Public Administration, Hebei University of Economics and Business \\ * Kang Jianying (1972-), male, born in Dingzhou, Hebei province, doctor, professor. Email: kjy001@126.com
}

\begin{abstract}
With the intensification of population aging and the expansion of employment time and space distance and other reasons, the function of the elderly in rural families has been continuously weakened. Although the assistance of institutions is provided, the dilemma that the demand for elderly services exceeds the supply is still severe. This article analyzes the real dilemma and reasons of rural mutual assistance for the elderly, and constructs the overall framework and realization path for the realization of mutual assistance for the elderly. It believes that government system innovation and resource integration are important guarantees for the sustainable development of mutual assistance for the elderly.
\end{abstract}

Keywords: Mutual assistance for the aged, Real dilemma, Solution path

\section{INTRODUCTION}

With the increase in the degree of aging in China, the spread of the distribution of employment space, and the increasing intergenerational differences in ideological life concepts, the function of family care for the elderly has been weakened. It is also not enough to change the age structure of the family population to improve the effect of family pension by adopting the childbirth policy within a period of time. Therefore, it is particularly necessary to actively explore multiple methods of pension, especially mutual assistance.

The concept of mutual assistance for the aged has existed in ancient Chinese "yes", but it is limited by the old economic and social development conditions, and the scope and level of protection are limited. With the deepening of population aging in Western countries and the changes in pension methods [1], the "time bank" model [2] was introduced to my country, and since the 1990s, my country has also the service form of mutual assistance for the elderly has emerged. Based on the absorption of foreign experience, the form of mutual assistance for the elderly with local characteristics has been born, such as the Beijing model, the Xingtai model and the Shanghai model. From the perspective of the regional evolution of mutual assistance for the elderly, these models were originally born in the cities and continue to radiate to the countryside, forming an irregular point-like distribution. From the perspective of the stage of development, the mutual assistance model has fallen into a calm period or even a shrinking period after the rapid development of the 1990s, and the total scope of promotion is limited; from the effect of implementation, the demand for mutual assistance is greater than the supply. The effect of spontaneous development is difficult to form an important support for the elderly [3]. Based on the above development practice of mutual assistance for the elderly in my country, it can be found that the concept of mutual assistance for the elderly is still in the initial stage of development, with insufficient innovation motivation, limited sustainability, and stagnation in the low-level discovery trap. Therefore, how to integrate existing resources and enhance the sustainability of mutual assistance is the focus of the current rural mutual assistance pension reform.

\section{THE DEVELOPMENT REALITY AND PREDICAMENT OF RURAL MUTUAL ASSISTANCE FOR THE AGED}

\subsection{Lack Of Policies Restricts The Expansion And Sustainability of Mutual Assistance Behavior}

Mutual assistance for the elderly is mainly reflected in inter-generational support. Although it contains "altruistic" elements in values, it is more "self-interested". Individuals use labor "storage" in the life cycle to 
exchange equivalent and intergenerational future pension services to realize self-care. This theoretically feasible "time bank" model has encountered a development bottleneck in my country, and the balance of supply and demand spontaneously. The mechanism is difficult to realize, which limits the expansion of the service scale. The specific problems are mainly reflected in the following points:

\subsubsection{The Lack Of Mutual Assistance Information Platform Construction, Scale Expansion Is Subject To Labor Measurement And Fulfillment}

Judging from the current experience in the construction of mutual assistance elderly care in various regions, the stagnant development and uneven regional distribution indicate that the acceptance of mutual assistance elderly care varies significantly, and various risks have caused a situation in which demand exceeds supply. The mutual assistance elderly care market fails, and government intervention is imperative. In 2011, 2013, 2016 and 2019, the State Council issued different policies on the issue of mutual assistance for the elderly, aiming to promote mutual assistance services for the elderly. However, there are still system deficiencies in terms of mutual assistance platform construction. It is because of changes in the occupational flow of personnel and the change of residence that the realization of measurement is more difficult to achieve. Mutual assistance services can only stay in a small area, low level, and simple services that rely on the feelings of the neighbors [4].

\subsubsection{Low Government Subsidy Standards And} Differences In Regional Resource Endowments Limit The Self-Realization Mechanism Of Mutual Assistance

At present, the realization forms of mutual assistance for the elderly in rural areas are mainly embodied in mutual happiness homes, stronghold activities, time banks, and paired circle models (the latter three are more commonly used in cities). The hardware construction of these realization modes mainly depends on communities and collectives, and government subsidies Less, which means that the realization of mutual assistance for the elderly can only rely on oneself (of course, mutual assistance itself belongs to autonomy), but the mutual assistance service market mechanism is difficult to achieve a high level of equilibrium, unable to bear the challenges brought by aging, and will be at a low level For development traps, only with the help of government subsidies and the implementation of the system can mutual aid services take off.

\subsubsection{Lack Of Industry Standard Construction, And The Quality Of Mutual Assistance Elderly Care Cannot Meet The Demand}

China's mutual assistance for elderly care originated from the private initiative. Although the central government has continuously introduced relevant policies in the past ten years, the establishment of industry rules for mutual assistance for elderly care is lagging, industry risks have increased, and service quality and level are difficult to meet the needs of aging, especially in industry construction. Details such as the allocation of resources, the power and responsibilities of both the supplier and the demander, the ownership and supervision of mutual assistance management authority, the standards of service quality, and the docking of policies are all in urgent need of scrutiny and demonstration, so as to enhance the operability and implementation effects of the policy.

\subsection{The Concept Of Mutual Assistance For The Elderly In Rural Areas Is Weak, And The Scope And Realization Of Mutual Assistance Are Limited}

The rural fertility rate is higher than that of the city, the family structure model is diversified, the family intergenerational support is relatively strong compared to the city, and the neighbor relationship and blood relationship in the human relationship society support the family's support for the elderly. The rural areas are not very active in accepting mutual assistance for the elderly, so the promotion of mutual assistance services has certain difficulties [5].

\subsubsection{The Coverage Of Policy Propaganda Is Limited, And The Concept Of Mutual Assistance For The Elderly Has Not Penetrated Into The Grassroots.}

As the state has increased its support for the construction and operation of pension institutions, the institutional pension model in rural areas has been widely accepted, especially for disabled and semi-disabled elderly people and families with better economic conditions. The sources of information about the form of mutual assistance for the elderly are still scattered and informal channels, and the role and form of mutual assistance for the elderly are basically in a blind spot. This shows that the national mutual aid policy publicity and support have not yet penetrated into the cognition of the grassroots and the general public. The pilot demonstration effect and diffusion effect of mutual assistance for the elderly are also very limited. At present, mutual assistance for the elderly has limited support for the family's elderly care function. 


\subsubsection{The Realization Form Of Mutual Assistance Is Single, And It Is Difficult To Form A Sustainable Scale Effect}

The current pilot concept of mutual assistance for the elderly in rural areas is rooted in traditional human sentiments and ethics, with the help and feedback between neighbors, blood and marriage as the main model, and the service content is limited to simple daily care and spirituality. Consolation, this broad form of mutual assistance is small in scale, low in professionalism, and strong in sporadicity. It is popular in relationships with families and in-laws, and is subject to the influence of family population size, occupational structure, and economic and social status. This simple form of mutual assistance is difficult to form a large-scale, inter-generational, and sustainable form of mutual assistance, which limits the upgrading and scale effect of mutual assistance content.

\subsubsection{The Lack Of Professional Training In} Mutual Assistance Elderly Care Services, Moral Hazards And Conflicts Limit The Balance Of Supply And Demand

The content of elderly care services is very rich and requires professional practical skills as support. However, the professional training of rural elderly care service personnel is very lacking. The service forms are mostly limited to traditional housework, and the service quality cannot keep up with the diversified needs. In addition, the employment of rural left-behind people is mainly to earn salaries, and there is a shortage of labor services for professional or part-time mutual assistance, and the majority of them are women, which is difficult to meet the needs of male elderly people. Furthermore, due to the relative privacy of the home care service environment, there are some infringements and service risks, which are not convenient for the development of mutual assistance for the elderly, so non-professional short-term service quality cannot meet the needs of mutual assistance for the elderly.

\section{THE OVERALL FRAMEWORK DESIGN OF RURAL MUTUAL ASSISTANCE FOR THE ELDERLY}

According to the development experience of urban mutual assistance for the elderly, the smooth development of rural mutual assistance for the elderly needs to start with the framework mechanism of "system innovation-resource integration-technology platform", that is, the exchange of labor and capital, the innovation of mutual assistance system, and the integration of retirement resources. Only the coordination of the three can guarantee the smooth implementation of mutual assistance for the aged in rural areas.

\subsection{Respect For The Market Value Of Labor Services Is The Prerequisite For Mutual Assistance For The Elderly, And Capital Exchange Is The Driving Force For The Balance Of Supply And Demand.}

China's current realization of mutual assistance for the elderly requires more than demand. The idle old-age resources and the fragmentation of the system have led to a relatively largescale effect and sustainability of mutual assistance. Respect market prices, realize the integration of mutual assistance resources for the elderly through labor exchanges, and reduce moral hazard through two ways of saving and intertemporal cashing in labor services, and monetization of paid labor payments . And market risks, and stimulate the automatic stimulation and circulation mechanism of mutual assistance for the elderly. Among them, the definition of the value connotation of labor measurement, currency exchange, and discounting is the prerequisite for mutual assistance services to occur under cross-generational, cross-period, and cross-regional conditions. Fully respecting the market value of labor is conducive to the expansion and improvement of the scale of mutual assistance for the elderly service quality.

\subsection{Institutional Innovation Is The Guarantee For The Operation Of Mutual Assistance, And The Intervention Of Social Organizations Is The Engine Of Standardized Construction}

At present, the overall situation of mutual assistance pensions in China is stagnant, and the scale expansion and demonstration effect are far less than the popularization and acceptance of institutional pensions. This low-level development trap requires policy guidance and support, and is aimed at the planning, operation and development of mutual assistance pensions. Targeted formulation of policies in each link, not only must draw on foreign advanced experience, but also respect the reality of rural development, innovative realization, the joint participation of the market, government and social organizations, integration of pension resources, improvement of mutual assistance and pension industry norms, and expansion of mutual assistance Service supply combines mandatory system changes with induced system changes to achieve a balanced supply and demand and automatic operation of rural mutual assistance for the elderly.

\subsection{Integrating Old-Age Resources Is The Cornerstone Of Mutual Assistance, And The Solution Of Resource Shortage Requires The Integration Of Multiple Welfare Systems}

The general problem of rural family care for the elderly is daily care and nursing, while the problem of 
institutional care is reflected in economic support. Mutual support for the elderly can effectively embed the above two basic models, saving family resources and improving the quality of life of the people in need. However, due to the limited scale of mutual assistance platforms and the lack of industry norms, risk prevention makes it difficult to guarantee the scale and continuity of mutual assistance. For this reason, it is necessary to coordinate and expand basic pension resources: idle labor, pensions, government subsidies, social donations, and collective benefits. To achieve immediate labor monetization or inter-period labor exchange and inter-period currency labor exchange, and reduce the risk and uncertainty of mutual pensions.

\section{THE REALIZATION PATH OF RURAL MUTUAL ASSISTANCE FOR THE ELDERLY}

According to the realization mechanism of rural mutual assistance for the elderly, it can be seen that the realization, scale expansion and sustainable development of mutual assistance for the elderly need to make breakthroughs from the following paths.

\subsection{Straighten Out Inter-Governmental Financial Support Responsibilities And Increase Financial Investment In Infrastructure}

The infrastructure of rural mutual assistance for the aged can be supported by families, institutions, or other innovative forms. The specific operation method is realized according to the resource endowment conditions of various places. Governments at all levels allocate specific financial allocation plans according to the needs of the population, through financial allocation, supporting facilities, tax deductions, etc. Methods to strengthen the construction of infrastructure, clarify the construction goals and the relationship of power and responsibility. In addition, it is necessary to strengthen the supervision of the use efficiency of pension alms, hardware and software construction.

\subsection{Use Blockchain Technology To Build A Mutual Aid Information Platform To Create The Cashing And Measurement Of Labor And Currency}

The construction of the information platform involves the measurement and fulfillment of the service area, which affects the scale and sustainability of mutual assistance, especially with the acceleration of labor employment and the accompanying family migration, so the information platform technology based on blockchain technology can be effective Realize the registration, measurement and transfer of cross-regional mutual assistance elderly care services, laying the foundation for sustainable development. In addition, labor services can also be combined with the pension and medical systems of the social security system to realize currency exchange and medical and health exchange for labor services [6], combined with the tax system, and reduce the personal tax threshold for labor services. Further incentivize the supply scale of mutual assistance for the elderly.

\subsection{Strengthen The Cooperation Between The Government And Social Organizations, And Improve The Industry Norms of Mutual Assistance Services For The Elderly}

Although mutual-living for the elderly is not a new model of elderly care services, the current service standards and system construction in this industry are far from taking shape, especially in rural areas. Therefore, system construction and innovation are particularly urgent. First, cooperate with professional social organizations to establish industry standards for mutual assistance for the elderly, including operating specifications, qualifications, professional ethics and evaluation mechanisms. Second, the government promotes the quality of rural mutual assistance services by purchasing professional public services. Social work services and some medical care services have an important position in the elderly care industry. In the early stage of the development of rural mutual aid elderly care, the space can be purchased through advertising, so that it can be embedded in the rural mutual aid market, and the industry's standardization can be quickly improved.

\subsection{Exploring Family And Collective Pension Resources To Accelerate The Effective Docking And Integration Of The Welfare System}

The rural mutual assistance pension resources are scattered and limited, and it is necessary to integrate existing resources. First, in terms of hardware construction, governments at all levels use the collective land of the village to build the places needed for mutual assistance for the elderly through financial allocations, and hand them over to community organizations for use; second, they combine rural labor services with collective welfare, basic pension systems and other systems to promote labor and Exchange between currencies; in addition, it can also unify the value of land transfer, homestead and other factors with the value of labor services. Finally, extensive efforts will be made to strive for social resources, food, transportation, and mutual assistance for the elderly.

In the last century, my country's mutual assistance for the elderly has begun to experiment and some typical pilots have appeared, which have achieved a good social response. However, due to the impact of unbalanced supply and demand, the scale of mutual assistance is 
difficult to develop, and unsustainability has caused some pilots to shrink and survive in name. This is especially true of mutual assistance for the elderly in rural areas. Therefore, on the basis of scientific policy guidance and financial support, the involvement of professional organizations and the extensive participation of farmers, the establishment and improvement of industry norms, through incentives and exchange mechanisms to achieve mutual aid scale effect, to achieve a balance of supply and demand , to provide assistance to families and institutions for the elderly to improve the quality of life of the elderly.

\section{CONCLUSIONS}

Rural mutual assistance for the elderly is an important practice to effectively integrate various social support resources in rural areas. The mutual assistance model for the elderly can effectively solve the rural elderly's elderly care problems with its unique advantages. However, the current practice has insufficient innovation motivation, limited sustainability, and Issues such as a weak concept of mutual assistance. Through analysis, this article believes that the implementation of rural mutual assistance for the elderly needs to be guaranteed by system innovation, based on resource integration, guided by the design and operation of technical platforms, and through the cooperation of government and social organizations, strengthening the exchange of labor and capital can only be limited. To solve the imbalance between the supply and demand of elderly care services under the resources of the country, the integration of elderly care resources and the innovation of technology and systems are the keys to ensuring the large-scale implementation of mutual assistance elderly care.

\section{ACKNOWLEDGMENTS}

This study is supported by the National Social Science Project: Research on resource integration, system innovation and sustainability of rural mutual pension (20BSH020).

\section{REFERENCES}

[1] Jiang Jingchuan. Research on Intergenerational Relations from the Perspective of Active Aging Abroad[J]. Foreign Social Sciences, 2014 (7): 23-29.

[2] Gill Seyfang, Working Outside the Box: Community Currencies, Time Banks and Social Inclusion, Journal of Social Policy, Vol. 33, 2004, pp. 49-71.

[3] He Xuefeng. Mutual support for the elderly: the way out for the elderly in rural China[J]. Journal of Nanjing Agricultural University (Social Science Edition), 2020, 20(05):1-8.

[4] Shi Renbing, Wang Jun, Liang Xunchang. From "mutual assistance" to "reciprocity": the way out for elderly care in economically underdeveloped rural areas [J]. Social Security Research, 2020(03): 34-40.

[5] Ji Chunyan. The advantages, difficulties and countermeasures of the development of rural "time bank" pension model[J]. Theoretical Journal, 2020(05): 140-148.

[6] Peng Yanhui. Intergenerational double binding time bank: a new model of rural elderly care services[J]. Northwestern Population, 2017, 38(06): 87-92. 